\section{A EVOLUÇÃO QUIMICA COMO PARTE INTEGRANTE DO CURRICULUM NO ENSINO DAS CIÊNCIAS QUÍMICAS}

O termo Evolução Química apareceu na literatura científica há cerca de 30 a 40 anos, para descrever alguns processos observados na natureza. Por um lado, no âmbito restrito da geologia, procura definir o período de tempo que precede a Evolução Biológica, isto é o chamado "estádio prebiológico" correspondente aos primeiros mil milhð̄es de anos depois da formação da Terra; seria neste período que, de acordo com um certo consenso existente, teria ocorrido a síntese das principais espécies químicas que viriam a constituir a biosfera em períodos mais tardios em que se formaram as primeiras células biológicas observadas nos mais antigos sedimentos conhecidos na Terra e que datam de há mais de três mil milhø̃es de anos. Por outro lado, o termo Evolução Química refere-se à definição dos mecanismos de formação espontânea de moléculas biologicamente importantes, independentemente do período geológico em que esta formação ocorre. É o caso, por exemplo, da síntese dos aminoácidos essenciais realizada na célebre e frequentemente citada experiência de Miller a partir da interacção de descargas eléctricas com misturas gasosas de amónia, metano e água. Desde então foram publicadas milhares de reacçð̃es químicas para demonstrar a possibilidade de produzir aminoácidos simples, pirimidinas, purinas, hidratos de carbono, etc., utilizando fontes de energia mais ou menos subtis tais como calor, ondas de choque, radiaçð̃es electromagnéticas e muitas outras. Independentemente das definiçø̃es específicas, é evidente que esta noção de "evolução química" aponta para os problemas fundamentais da "origem da vida". É óbvio que para discutir a "origem da vida" é necessário encontrar consenso numa definição clara do termo "vida" ou, talvez ainda mais rigorosamente, na definição da distinção entre um sistema vivo e um sistema não vivo. Torna-se imediatamente claro que esta questão é um dos problemas essenciais de toda a ciência. Uma vez que a definição de Vida fique estabelecida sem ambiguidade (e estamos ainda longe disso!) um grande conjunto de problemas e questðos básicas poderão começar a ser reformuladas e naturalmente esclarecidas a partir dessa definição: Onde começou a Vida - na Terra ou noutro lugar? Quando começou a Vida na Terra ou noutro lugar? A informação dos sistemas vivos estaria impressa desde o princípio do Universo, desde o próprio Big-Bang? Poderemos ter a esperança (ou medo?) de criar um sistema vivo em laboratório - em vez de simplesmente simularmos alguns processos relacionados que só de forma muito remota se assemelham aos mecanismos envolvidos no processo de
Wolfram H.-P. Thiemann(*)

criação da vida? A minha opinião pessoal a este respeito é que, apesar de termos atingido um conhecimento formidável sobre a estrutura dos sistemas vivos, estamos ainda muitíssimo longe da criação genuína da vida. Certamente que existem autores que discordarão desta minha afirmação, como por exemplo M. Eigen e S. Fox que reclamaram de um modo mais ou menos dissimulado terem chegado muito próximo de gerar um "tipo de máquina com vida" ou uma "verdadeira célula tal como o defino!'. Penso que estes ou outros cientistas (em particular os bioquímicos que trabalham em proteinas e em genética) foram bastante longe e obtiveram grande sucesso no estudo pormenorizado da estrutura dos sistemas vivos, na análise e na separação de componentes específicos, chegando mesmo a utilizar estes componentes separados (retirados de sistemas biológicos!) reintroduzindo-os em células vivas funcionais.

A disciplina Evolução Química, que se tem vindo a circunscrever e a definir no sentido indicado anteriormente, é tipicamente um domínio científico moderno na medida em que não se enquadra no panorama das disciplinas clássicas como a química inorgânica, a orgânica ou a física, a biologia molecular, a genética, a física experimental ou nuclear, a astrofísica, a astronomia e disciplina similares.

Num certo sentido a disciplina Evolução Química, isto é o estudo das possíveis origens da vida, poderia voltar a unificar várias disciplinas científicas sob um mesmo denominador comum, disciplinas essas que foram separadas ou compartimentadas ao longo do próprio desenvolvimento histórico da ciência. Esta compartimentação é tal que os membros de uma dada comunidade científica têm normalmente dificuldade em entender os membros de uma comunidade científica vizinha devido à especificidade da terminologia da cada uma delas. As relaçб̃es entre biologia molecular e fisiologia, entre química-física e química orgânica, entre física nuclear e termodinâmica, podem ser apontadas como exemplos típicos dessa Babilónica confusão de linguagem que reina na comunicação científica. Por outro lado, dado que o problema da origem da vida está intimamente relacionado com problemas básicos da filosofia, da astronomia (origem da matéria e das estrelas!), da cosmologia, da física teórica, da mecânica e da termodi-

(*) Fachereich Chemie-Physical. Chemie, Universität Bremen - NW 2, D 2800 BREMEN 33, RFA. 
nâmica (o conceito de entropia!), da química orgânica e inorgânica, da biologia molecular (a origem do código genético!), da neurologia, fisiologia e antropologia (origem do cérebro, origem do homem!), e de muitas outras disciplinas, a Evolução Química constitui um tema ideal para o estudante e o investigador que tenha um espirito suficientemente aberto para embarcar na aventura excitante que consiste em reunir novamente toda a ciência em torno de um objectivo merecedor.

\section{A EVOLUÇÃO QUÍMICA E O CURRICULUM NO SISTEMA EDUCATIVO ALEMÃO}

Embora a definição de Evolução Química no sentido acima exposto seja um assunto ideal para ser integrado nos curricula de qualquer sistema educativo do ramo científico, tanto ao nível secundário como universitário, é muito raro encontrarmos tais matérias nos cursos dos liceus ou universidades.

A razão deste facto resulta de os sistemas de educação superior na Alemanha(1) serem estruturados de um modo extremamente tradicional. Existem alguns locais restritos onde se podem encontrar cientistas que se dedicam aos problemas relacionados com a origem da vida e áreas afins, mas tal não acontece geralmente nas Universidades tradicionais mas antes em alguns Institutos Max Planck como o muito conhecido Instituto Max Planck de Química Biofísica em Göttingen, onde reside um dos poucos laureados com o prémio Nobel ainda activo: Manfred Eigen. No contexto do Curriculum Universitário pode encontrar-se aqui e ali alguma actividade, embora modesta, quando existe algum docente que tenha a coragem de remar contra a maré, como acontece nas Universidades de Franckfurt (Bücker), Mainz (Dose), e Bremen (o autor). Mesıno nestes casos as actividades são bastante restritas e estão mais ou menos escondidas ou dissolvidas em departamentos tradicionais como o de bioquímica, de química-física, de paleontologia, etc. Neste aspecto a situação alemã é completamente diferente da de outros países onde não há obstáculos semelhantes que impeçam o desenvolvimento de departamentos dedicados totalmente à investigação sobre a Evolução Química ou As Origens da Vida. Gostaria de mencionar os esforços da Universidade de Maryland nos E.U.A. onde existe um grande laboratório totalmente devotado ao estudo da Evolução Química (Director: C. Ponnamperuma), e da Universidade de Nijmegen na Holanda em que existe, como objectivos semelhantes, um departamento de exobiologia (Director: A. Schwartz). Em geral a população universitária alemã é relutante a entregar-se a novas áreas científicas - consideradas como interessantes mas demasiado arriscadas - e a abandonar o terreno já batido das carreiras universitárias tradicionais nos campos clássicos. Tenho tentado, em várias ocasiðes, criar na Alemanha actividades laboratoriais dirigidas para uma investigação deste tipo, mas infelizmente, até agora, com muito pouco êxito. Na minha própria Universidade tais esforços são encarados com o maior cepticismo; muitos colegas oferecem a sua simpatia pessoal por este domínio "bastante especulativo e pouco proveitoso", mas tudo fazem para evitar o mais pequeno avanço no sentido de integrar a evolução química no curriculum universitário alemão.

«Deixe-se dessas coisas e faça algo de mais respeitável» é o tipo de conselho que mais frequentemente ouço dos meus colegas. Embora exista um amplo consenso entre os cientistas alemães sobre a grande importância da ciência fundamental, verifica-se que o suporte financeiro e burocrático é quase exclusivamente dedicado às chamadas ciências aplicadas, e a evolução química está sem dúvida fora da definição de ciência aplicada. Por ciência aplicada entende-se algo que conduza a um rendimento imediato no âmbito da química, da física ou da tecnologia.

$\mathrm{Na}$ Alemanhá foram realizadas diversas experiências de reforma do sistema escolar, mas essas reformas têm que ver principalmente com a estrutura curricular e com os métodos de ensino e aprendizagem das disciplinas tradicionais; infelizmente nunca houve uma discussão alargada no sentido de introduzir novas matérias tais como a origem da vida ou outros. É por esta razão que não existe, pelo menos que eu saiba, um único curso deste tipo ao nível do ensino secundário ou liceal alemão. $\mathrm{O}$ desenvolvimento no pós-guerra foi tal que as ciências naturais foram empurradas e deixadas para trás, sendo encaradas como matérias dificeis, em favor das matérias fáceis, como as ciências sociais, ciências do ambiente, etc. Por isso não vejo actualmente qualquer hipótese de introduzir o tema da Evolução Quimica nas escolas liceais alemãs e creio aliás que todo o sistema de ensino a isso se oporia. A situação no secundário é pois, actualmente ainda mais desfavorável que no nível universitário.

\section{EXPERIÊNCIAS PRÁTICAS}

Há dois anos introduziu-se no curriculum do departamento de química da Universidade de Bremen um curso sobre «Origens dos Sistemas Biológicos - um Tópico Especial em Química-Física». O curso é constituído por duas horas semanais de aulas teóricas e três horas semanais de trabalhos laboratoriais, funcionando apenas no semestre de Verão e totalizando cerca de dez semanas. O curso está aberto a estudantes já licenciados e com uma sólida formação em química geral e química-física. O ensino é constituído por uma introdução à cosmoquimica (isto é à síntese dos elementos químicos, à origem da matéria e do Universo, e à hipótese do big-bang em comparação com a do estado estacionário), introdução esta que conduz à discussão da síntese espontânea das moléculas biológicas monoméricas a partir do metano, água, amónia, etc., e da policondensação e polimerização destas para formar os percursores dos biopolímeros. Dedica-se ainda algum tempo à análise dos fundamentos teóricos e dos princípios subjacentes à evolução da informação e da ordem biológica, baseados nas teorias desenvolvidas por M. Eigen, I. Prigogine, H. Kuhn e outros.

O trabalho laboratorial está planeado no sentido de dar uma ideia de como a síntese dos aminoácidos a partir dos seus percursores se pode realizar pela acção de fontes energéticas diferentes e específicas, principalmente descargas eléctricas e calor. Oferece-se ainda aos estudantes uma demonstração da formação expontânea de estruturas químicas espacio-temporais através de reacçōes oscilantes do tipo das de Zhabotinski-Belousov. O fenómeno da quiralidade é abordado como exemplo característico de informação (ou ordem) biologicamente significante; os problemas das estruturas quirais e da retenção de configuração nos processos biológicos são estudados pormenorizadamente através de métodos espectroscópicos. Considerando o tempo restrito atribuido a este curso em Bremen em comparação com o restante curriculum da química extremamente compacto e obrigatório (contrariamente ao curso sobre "A Origem 
dos sistemas Biológicos"' que é opcional), pouco se pode esperar do que pode ser ensinado nestas condiçøes limitadas.

Se um dia se puder chegar a um amplo consenso entre os químicos e cientistas de áreas relacionadas sobre a integração da Evolução Química como parte fundamental e integrante da química, esforçar-me-ia pessoalmente pela introdução desta matéria numa fase inicial do curriculum universitário (por exemplo no $2 .^{\circ}$ ano da Universidade). A Evolução Química seria uma cadeira obrigatória a ser introduzida tanto a nível introdutório como (mais tarde) a nível avançado. Penso que resultaria imediatamente da parte dos alunos um grande aumento de motivação e interesse pelos problemas mais fundamentais da química e da ciência em geral. Posso prever que os colegas dos departamentos de física, matemática, astronomia, filosofia, geologia se uniriam nesse esforço comum, e cada faculdade contribuiria para um curso introdutório àcerca de como ocorreu o começo da Vida na Terra (ou em qualquer outro lugar?). Teríamos assim mais uma grande oportunidade para ultrapassar o lamentável fosso existente entre as ciências naturais e a filosofia, para não mencionar muitas outras lacunas, mais estreitas mas igualmente profundas, existentes no seio das próprias ciências naturais e que possivelmente seriam ultrapassadas. Cientistas e estudantes poderiam reaprender a exprimir-se numa linguagem comum e a retomar formas de comunicação que se perderam há séculos! Estou plenamente convencido de que só este objectivo justificava o grande esforço exigido e possivelmente também contribuiria significativamente para a compreensão comum da origem da vida e da espécie humana e (inconscientemente!) para uma reformulação profunda do humanismo cosmopolita uma vez que então se aceitaria que o Homo sapiens tem realmente uma origem única e natural.

(1) Quando neste texto falamos de "Alemanha" ou "Alemão" referimo-nos apenas a observaçðes recolhidas na República Federal da Alemanha; no entanto a orientação tradicional no sistema educacional da República Democrática Alemã é igualmente forte.

\section{ORIGENS DA VIDA: ALGUNS PROGRESSOS E PROBLEMAS RECENTES}

É para mim um grande prazer contribuir com uma breve introdução para esta secção trimestral do Boletim da Sociedade Portuguesa de Química devotada às Origens da Vida. Não há dúvida de que o grau com que pudermos aplicar o conhecimento contemporâneo dos princípios químicos à compreensão da complexidade resultante da evolução dos organismos vivos é um teste às capacidades cognitivas da nossa ciência. Os meus parabéns e as maiores felicidades á Sociedade neste seu novo empreendimento!

A. I. Oparin foi o principal responsável pelo renascimento do interesse pela origem da vida como tema de investigação científica. A influência de Oparim e de H.C. Urey no trabalho de S.L. Miller e nas tentativas posteriores de estudo experimental da origem da vida foi documentada em muitos artigos de revisão e livros (ver, por exemplo, Miller e Orgel, 1974; Fox e Dose, 1977). As iumerosas conferências internacionais que se têm realizado sobre este tema constituem já uma tradição estabelecida, e as actas destes encontros constituem um registo fascinante do progresso neste campo (Clark e Synge, 1959; Fox, 1965; Buvet e Ponnamperuma, 1971; Oró e outros, 1974; H. Noda, 1978; Y. Wolman, 1981). Nos últimos anos os temas de interesse estendem-se por um largo espectro, desde a formação de moléculas simples até à atmosfera e hidrosfera primitivas até à auto-replicação de polinucleótidos e à origem do código genético. Estes temas ocupam os extremos mais afastados possíveis da série dos problemas exequíveis, uma vez que se referem
Alan W. Schwartz(*)

- em certo sentido - ao princípio e ao fim do periodo de evolução química.

\section{A COMPOSIÇÃO DA ATMOSFERA PRIMITIVA E O PROBLEMA DAS FONTES DOS REAGENTES CRÍTICOS}

As pedras básicas constitutivas dos sistemas biológicos são sintetizadas segundo uma lista particularmente reduzida de reacçס̄es envolvendo reagentes simples e correntes. Exemplos destas reacçðes são a formação de açúcares a partir de formaldeído (a reacção das formoses), a formação de certos aminoácidos, purinas e pequenas concentrações de uracilo, entre outros produtos, a partir de $\mathrm{HCN}$ (oligomerização de $\mathrm{HCN}$ ), e a síntese de uma grande variedade de amonoácidos a partir de aldeídos simples e $\mathrm{HCN}$ (sintese de Strecker). Na Figura 1 são sumarizados os esquemas mais importantes destas sinteses. Em algumas áreas torna-se necessário invocar alguns sistemas de reacçôes adicionais, tal como a síntese da citosina a partir de cianoacetaldeído e guanidina. Todos estes reagentes são produzidos directamente em atmosferas modelo constituídas por $\mathrm{N}_{2}$ e pequenas concentraçōes de $\mathrm{CH}_{4}$ e $\mathrm{H}_{2} \mathrm{O}$, excepto a guanidina que é um produto da oligomerização de HCN. Existem contudo grandes dúvi-

(*) Laboratory of Exobiology, Faculty of Science, The University, Nijmegen, Holanda. 